\title{
Connectivity and seasonality: the 1918 influenza and COVID-19 pandemics in global perspective ${ }^{\dagger}$
}

\author{
Siddharth Chandra, Julia Christensen and Shimon Likhtman
}

Asian Studies Center, Michigan State University, 427 North Shaw Lane, Room 301, East Lansing, MI 48824, USA E-mail: chandr45@msu.edu, James Madison College, Michigan State University, 842 Chestnut Rd, East Lansing, MI 48825, USA E-mail: chris591@msu.edu and James Madison College, Michigan State University, 842 Chestnut Rd, East Lansing, MI 48825, USA E-mail: likhtman@msu.edu

\begin{abstract}
The goal of this article is to demonstrate the value of a global perspective on pandemics for understanding how global pandemics caused by novel viruses can unfold. Using the example of the 1918 influenza pandemic, two factors that were central to the evolving pattern of global pandemic waves, connectivity and seasonality, are explored. Examples of the influences of these factors on pandemic waves in different locations are presented. Viewing the 1918 pandemic through the lens of compartmental models of infectious diseases, our analysis suggests that connectivity played a dominant role in the initial stages. With the passage of time and the progressive infection and consequent immunization of more and more people, however, the role of seasonality increased in importance, ultimately becoming the driving force behind the emergence of future waves of infection. Implications of these observations for pandemics caused by novel viruses such as the ongoing COVID-19 pandemic are discussed.
\end{abstract}

Keywords: 1918 influenza pandemic; colonial networks; COVID-19 pandemic; epidemics; First World War; seasonality

\section{Introduction}

The influenza pandemic of 1918-20 was the single most devastating pandemic of the twentieth century. ${ }^{1}$ In just a year it killed an estimated 50 million people worldwide, and successive waves of infection and mortality dragged on around the globe for at least two years after the first outbreak. ${ }^{2}$ This pandemic (which we will refer to as 'influenza-18' for brevity) was remarkable not only for its size, measured in numbers of cases and deaths, or because it was a truly global phenomenon, but also because descendant strains of the then novel H1N1 virus that caused it remain in circulation even today. These ominous characteristics earned the influenza-18 pandemic the title 'Mother of All Pandemics'. ${ }^{3}$ However, it was soon overshadowed by other major global events, including the

\footnotetext{
${ }^{\dagger}$ We are grateful for Professor Ewout Frankema's comments on earlier drafts of this article.

${ }^{1}$ Damir Huremović, 'Brief History of Pandemics (Pandemics Throughout History)', in Psychiatry of Pandemics, ed. D. Huremović (Cham: Springer, 2019), 7-35; Centers for Disease Control and Prevention, National Center for Immunization and Respiratory Diseases (hereafter cited as CDC, NCIRD), Division of Viral Diseases, '1918 Pandemic (H1N1 Virus)', https://www.cdc.gov/flu/pandemic-resources/1918-pandemic-h1n1.html.

${ }^{2}$ Alfred W. Crosby, America's Forgotten Pandemic (Cambridge: Cambridge University Press, 1989); K. D. Patterson and G. F. Pyle, 'The Geography and Mortality of the 1918 Influenza Pandemic', Bulletin of the History of Medicine 65 (1991): 4-21; N. P. A. S. Johnson and J. Mueller, 'Updating the Accounts: Global Mortality of the 1918-1920 “Spanish" Influenza Pandemic', Bulletin of the History of Medicine 76 (2002):105-15.

${ }^{3}$ Jeffery K. Taubenberger and David M. Morens, '1918 Influenza: The Mother of All Pandemics', Emerging Infectious Diseases 12, no. 1 (2006): 15-22.
}

(c) The Author(s), 2020. Published by Cambridge University Press. 
Great Depression and the Second World War. Indeed, by the late twentieth century, a leading historian had called the influenza-18 pandemic a 'forgotten pandemic'. ${ }^{4}$

Such was the state of affairs in 2018, the centenary of the influenza-18 pandemic. At that time, existing work on the pandemic received renewed attention - predominantly in academic circles but with some attention from the media as well. ${ }^{5}$ With the arrival of the COVID-19 pandemic in late 2019 and early 2020, however, interest in the 1918 influenza has dramatically increased. Work published prior to the COVID-19 pandemic has received renewed attention and vigorous discussion, thereby improving our understanding of both the influenza-18 and the COVID-19 pandemics, and providing more general lessons for the management of similar pandemics in future years. ${ }^{6}$

Recent scholarship on the influenza-18 pandemic has focused on comparisons with the COVID-19 pandemic. Similarities between the two events include the viral nature of both pandemics; the novelty of the viruses that caused them; their manifestation - established or expected in multiple waves of infection and mortality; and the absence of a vaccination or cure for the diseases at the time they emerged. A key similarity that explains why these viruses caused pandemics is their reproduction number, defined as the average number of people in a susceptible population who will be infected by an infected individual. If this number exceeds 1.0, then, on average, an infected person will go on to infect more than one other person, leading to the exponential growth of the number of cases and resulting in a wave of infections and deaths. In both influenza-18 and COVID-19, the reproduction number has been estimated to be well in excess of 1.0 .

There are, of course, many significant differences between influenza-18 and COVID-19, including the viruses themselves and their impacts on patients, manifested in a variety of ways. ${ }^{7}$ For example, a signature feature of influenza-18 was its disproportionate impact on people in the prime of their lives (aged twenty to forty years). ${ }^{8}$ An unfortunate consequence of this was the toll it took on pregnant women, with spikes in deaths during childbirth, preterm births, and stillbirths at the time that mortality was peaking. ${ }^{9}$ The COVID-19 pandemic appears to be disproportionately harmful to older people, with a different but equally devastating set of implications. ${ }^{10}$

A striking feature of research on the influenza-18 pandemic is the overwhelming presence of single-country studies or studies of a few countries, which typically focus on country-specific

\footnotetext{
${ }^{4}$ Crosby, America's Forgotten Pandemic.

${ }^{5}$ Cécile Viboud and Justin Lessler, 'The 1918 Influenza Pandemic: Looking Back, Looking Forward', American Journal of Epidemiology, 187, no. 12 (2018): 2493-7; Rollins School of Public Health, Emory University, and CDC, '1918 Pandemic Flu Symposium Agenda', 7 May 2018, https://www.cdc.gov/flu/pandemic-resources/1918-commemoration/agenda.htm; Vanderbilt University Medical Center and Human Vaccines Project. 'Agenda for "Towards a Universal Influenza Vaccine: Lessons from the Great Influenza Pandemic of 1918 to Now: What Do We Know, and What Do We Need to Know?"', 15-16 November 2018, https://www.humanvaccinesproject.org/wp-content/uploads/2018/10/Agenda_Website. pdf; BBC News: World Service, 'Pandemic: The Story of the 1918 Flu', 13 January 2018, https://www.bbc.co.uk/ programmes/w3cswdhh.

${ }^{6}$ BBC News: World Service, The Forum, 'The 1918 Spanish Flu: The Mother of All Pandemics', 30 April 2020, https://www. bbc.co.uk/programmes/w3cszjv8.

${ }^{7}$ Stephanie Soucheray, “'Great Influenza” Author Talks COVID-19, 1918 Flu’, CIDRAP News, 10 April 2020, https://www. cidrap.umn.edu/news-perspective/2020/04/great-influenza-author-talks-covid-19-1918-flu.

${ }^{8}$ Cécile Viboud, Jana Eisenstein, Ann H. Reid, Thomas A. Janczewski, David M. Morens, and Jeffery K. Taubenberger, 'Ageand Sex-Specific Mortality Associated with the 1918-1919 Influenza Pandemic in Kentucky', Journal of Infectious Diseases 207 (2012): 721-9; Alain Gagnon et al., 'Age-Specific Mortality during the 1918 Influenza Pandemic: Unravelling the Mystery of High Young Adult Mortality’, PloS ONE 8, no. 8 (2013), https://doi.org/10.1371/journal.pone.0069586.

${ }^{9}$ Svenn-Erik Mamelund, 'Fertility Fluctuations in Times of War and Pandemic Influenza', Journal of Infectious Diseases 206, no. 1 (2012): 140-1; Siddharth Chandra, Julia Christensen, Svenn-Erik Mamelund, and Nigel Paneth, 'Short-Term Birth Sequelae of the 1918-1920 Influenza Pandemic in the United States: State-Level Analysis', American Journal of Epidemiology 187, no. 12 (2018): 2585-95; Alice Reid, 'The Effects of the 1918-1919 Influenza Pandemic on Infant and Child Health in Derbyshire', Medical History 49, no. 1 (2005): 29-54.

${ }^{10}$ CDC, NCIRD, Division of Viral Diseases, 'Older Adults', 25 June 2020, https://www.cdc.gov/coronavirus/2019-ncov/ need-extra-precautions/older-adults.html.
} 
conditions and phenomena, providing an in-depth view of how the pandemic unfolded in a localized area. While such studies provide valuable insights into the pandemic, ranging from its epidemiological characteristics to its historical and social impacts, they cannot offer the kinds of insights that a global perspective can. Unfortunately, works exploring the pandemic as a global phenomenon are far scarcer. The goal of this article is to demonstrate how a global perspective can enrich our understanding of the influenza-18 pandemic, and how this can also contribute to our understanding of the ongoing COVID-19 pandemic.

With this in mind, we focus on how the influenza-18 pandemic unfolded over time in different locations around the globe and some of the phenomena that likely played a role in this process. While we acknowledge that a multitude of factors influenced the specifics of the pandemic in different locations, we highlight two factors that are crucial for understanding the global wave structure of the pandemic: connectivity and seasonality. While it is impossible to marshal all the available data for the present study, as this would be a highly resource-intensive undertaking, given the volume of available material, we strategically selected material to illustrate the above point. It is hoped that a follow-up project will undertake such an endeavour in a more deliberate manner, using resources that are proportionate to the task.

The role of connectivity is clear in the context of pandemic waves caused by a novel virus. In order to attack a population, such a virus must either develop in situ or be introduced into the population. The prevailing wisdom is that the H1N1 virus, which caused the influenza-18 pandemic, developed on a farm in Kansas in the United States, spreading through the US Midwest in March and April 1918 and then on to locations across the globe. ${ }^{11}$ Therefore, understanding how the world was interconnected at the time is vital to understanding the spread of the pandemic and the appearance of waves in different locations.

A second and intriguing aspect of the influenza-18 pandemic is the role of seasonality in determining the wave structure of the pandemic across the globe. It is well established that influenza exhibits a highly seasonal pattern - hence the notion of a 'flu season' in temperate regions like the northern USA, which have marked seasons. ${ }^{12}$ Scholars have advanced various reasons for this seasonal pattern, including biological and behavioural ones. ${ }^{13}$ For example, it has been shown in the laboratory that the optimal conditions for the survival and propagation of influenza virus are cool temperatures and dry air of the kind that prevail in much of the USA in the autumn and winter seasons, especially when home heating systems are in use. ${ }^{14}$ On the behavioural side, cooler seasons are a time when people spend more time indoors and in closer contact with others, facilitating transmission. ${ }^{15}$ A global perspective allows us to assess the variation across the globe, from temperate regions in the northern hemisphere to the equator to temperate regions in the southern hemisphere, all of which experience markedly different seasons at any given time. This variation, along with patterns of connectivity and contact, can be of immense value in understanding how novel viruses manifest as pandemic waves as they come in contact with human populations, and

\footnotetext{
${ }^{11}$ John M. Barry, 'The Site of Origin of the 1918 Influenza Pandemic and Its Public Health Implications', Journal of Translational Medicine 2, no. 3 (2004), https://doi.org/10.1186/1479-5876-2-3. For discussion of alternative locations of origin, see also M. O. Humphries, 'Paths of Infection: The First World War and the Origins of the 1918 Influenza Pandemic', War in History, 21, no. 1 (2014): 55-81.

${ }^{12}$ CDC, NCIRD, Division of Viral Diseases, 'The Flu Season', 12 July 2018, https://www.cdc.gov/flu/about/season/fluseason.htm.

${ }^{13}$ E. Lofgren, N. H. Fefferman, Y. N. Naumov, J. Gorski, and E. N. Naumova, 'Influenza Seasonality: Underlying Causes and Modeling Theories', Journal of Virology 81, no. 11 (2007): 5429-36.

${ }^{14}$ Anice C. Lowen, Samira Mubareka, John Steel, and Peter Palese, 'Influenza Virus Transmission Is Dependent on Relative Humidity and Temperature', PLoS Pathogens 3, no. 10 (2007), https://doi.org/10.1371/journal.ppat.0030151.

${ }^{15}$ In addition, religious gatherings have been shown to be associated with propagation of the virus. See, for example, Mariam Elhussein, Samiha Brahimi, Abdullah Alreedy, Mohammed Alqahtani, and Sunday O. Olatunji, 'Google Trends Identifying Seasons of Religious Gathering: Applied to Investigate the Correlation between Crowding and Flu Outbreak', Information Processing and Management 57, no. 3 (2020), https://doi.org/10.1016/j.ipm.2020.102208.
} 
how these waves dissipate and new waves emerge over time as contact continues and the seasons change.

To the extent that COVID-19 is caused by a member of the coronavirus family, many of whose members show seasonal patterns of emergence, an understanding of the waves of the influenza-18 pandemic may also provide a foundation for understanding future patterns of emergence and reemergence of waves of COVID-19 across the globe. In order to have the widest variation in conditions in the following analysis, we considered a mix of countries from both the northern and the southern hemispheres, as well as countries closer to the equator which may not have had such marked seasonal variation.

\section{Summary of the global experience}

The influenza-18 pandemic is generally characterized as consisting of a 'herald' wave in late spring and early summer 1918, followed the same year by the deadly autumn wave, and then one or more subsequent waves in 1919 or $1920 .^{16}$ The pandemic was remarkable in the degree to which the waves were synchronized around the world across climate zones and hemispheres, particularly during the deadly autumn 1918 wave. The rapid spread of the virus can be attributed to the extensive, rapid movement of people on steamships and rail lines, including as part of the First World War, and the transmissibility of the H1N1 virus itself. ${ }^{17}$ One report from the Dutch East Indies highlights how rapidly the virus would spread once introduced to a population, accelerating 'explosively' into a full-blown epidemic within two weeks of the first cases being introduced by infected individuals arriving by sea. ${ }^{18}$ The same report concluded that the influenza is imported from the Straits Settlements', 'the quick spreading of the disease [across the island chain in just a few weeks] is quite in accordance with the rapidity of the mode of transport', 'the susceptibility of the population for infection', and 'the easy spreading of the virus ... by speaking, coughing, sneezing. ${ }^{19}$

This synchronicity, apparently caused by the speed with which the virus spread, may explain why the pandemic is often summarized as occurring in the spring of 1918 and the autumn of the same year, perhaps trailing off in early 1919 before re-emerging in early 1920 . However, the general description of the influenza-18 pandemic is disproportionately informed by the experiences of America and western Europe, leaving room to further refine our understanding by expanding the geographic scope of research. ${ }^{20}$

\section{Wave 1: the 'herald' wave}

After emerging in the USA in March 1918, the first wave or 'herald' wave of the pandemic reached Spain and France later that month. The rest of western Europe experienced a 'herald' wave between May and August, later in more northern latitudes and areas farther from the ports through which the virus entered the continent. ${ }^{21}$ Much of this spread occurred outside the regular

\footnotetext{
${ }^{16}$ Patterson and Pyle 'Geography and Mortality'.

${ }^{17}$ Ibid.

${ }^{18}$ Dutch East Indies, Public Health Service, Mededeelingen van den Dienst der Volksgezondheid in Nederlandsch-Indië (Communications from the Public Health Service in the Dutch East Indies) (Batavia, 1920), 147, 145.

${ }^{19}$ Ibid., 153, 143.

${ }^{20}$ K. David Patterson, 'The Influenza Epidemic of 1918-19 in the Gold Coast', Journal of African History 24, no. 4 (1983): 485.

${ }^{21}$ Patterson and Pyle, 'Geography and Mortality'; Siddharth Chandra and Julia Christensen, 'Preparing for Pandemic Influenza: The Global 1918 Influenza Pandemic and the Role of World Historical Information', Journal of WorldHistorical Information 3-4, no. 1 (2016-17): 20-30; United States Public Health Service (hereafter cited as USPHC), Public Health Reports Vol. 33, Part 1: January-June, 1918 (Washington, DC: Government Printing Office, 1919), https:// hdl.handle.net/2027/chi.16129390?urlappend=\%3Bseq=9; USPHC, Public Health Reports Vol. 33, Part 2: July-December, 1918 (Washington, DC: Government Printing Office, 1920), https://hdl.handle.net/2027/chi.78881066?urlappend=\%
} 
influenza season (October to April) in the northern hemisphere. ${ }^{22}$ The influenza reached India in May, and many countries in Asia and Oceania experienced a herald wave between June and July. There is less information on herald waves in the Caribbean and South America, though Brazil appears to have experienced one in June 1918. Information about Africa is even scarcer.

\section{Wave 2: the deadly autumn 1918 wave}

The second wave of the pandemic began in August in France and Spain, spreading to countries to the south, east, and north in September and October, and arriving in Russia in November. Reports of waves of infections continued into January and February 1919, extending later into the spring in colder, northern countries, including Sweden and parts of Russia. ${ }^{23}$ This aligns with our understanding of seasonality and the impact of climate on transmission: the wave began just before the European flu season, extended well into that season, and appears to have ended in most places before the end of the flu season in April and May. North America experienced the deadly autumn wave between August and December 1918, the specific timing varying across the continent. In some areas, the wave may have been a double-peaked wave or two waves moving through in quick succession. ${ }^{24}$ As in Europe, the autumn 1918 wave began just before the flu season, extended into it, and tapered off prior to its end.

An important difference between the epidemics in the US and Europe was that cities in the US were far more willing to deploy non-pharmaceutical interventions (NPIs) such as bans on public gatherings in order to slow or prevent the spread of the epidemic. This resulted in different mortality patterns: much of Europe saw a single large autumn wave, whereas many cities in the US experienced double-peaked waves resulting from the imposition and subsequent relaxation of NPIs. ${ }^{25}$ Differences in the timing of NPIs also contributed to lower mortality in some US cities. ${ }^{26}$ A well-known example of this is the contrast between Philadelphia and St Louis. Authorities in Philadelphia downplayed the epidemic and allowed a massive parade to go on. By the time that NPIs were put in place, the city's healthcare system was overwhelmed. ${ }^{27}$ In St Louis, NPIs such as school closures and cancellations of large gatherings were put into place soon after the city's first case was detected and were sustained for about ten weeks, resulting in a far smaller epidemic than in Philadelphia. ${ }^{28}$ In Michigan, Governor Albert Sleeper issued a state-wide order closing most

\footnotetext{
3Bseq=7; USPHC, Public Health Reports Vol. 34, Part 1: January-June, 1919 (Washington, DC: Government Printing Office, 1920), https://hdl.handle.net/2027/chi.16129403?urlappend=\%3Bseq=11; USPHC, Public Health Reports Vol. 34, Part 2: July-December, 1919 (Washington, DC: Government Printing Office, 1920), https://hdl.handle.net/2027/msu.31293104164 524? urlappend=\%3Bseq=5; USPHC, Public Health Reports Vol. 35 Part 1 January-June, 1920 (Washington, DC: Government Printing Office, 1920), https://hdl.handle.net/2027/hvd.hx3bx5? urlappend=\%3Bseq=7; USPHC, Public Health Reports Vol. 35, Part 2: July-December, 1920 (Washington, DC: Government Printing Office, 1920), https://hdl. handle.net/2027/chi.78881131? urlappend=\%3Bseq $=13$.

${ }^{22}$ Patterson and Pyle, 'Geography and Mortality'.

${ }^{23}$ USPHC, Public Health Reports, 1918-1920.

${ }^{24}$ Siddharth Chandra, Madhur Chandra, Julia Christensen, and Nigel Paneth, 'Pandemic Re-emergence and Four Waves of Excess Mortality Coinciding with the 1918 Influenza Pandemic in Michigan: Insights for COVID-19', in press, American Journal of Public Health, 2020; Coleman C. Vaughan, Annual Report on the Registration of Births and Deaths, Marriages and Divorces in Michigan for the Year 1918 (Lansing, MI: Wynkoop Hallenbeck Crawford Co., State Printers, 1920), https://hdl.handle.net/2027/hvd.hc5mlq?urlappend=\%3Bseq $=5$.

${ }^{25}$ Martin C. J. Bootsma and Neil M. Ferguson, 'The Effect of Public Health Measures on the 1918 Influenza Pandemic in U.S. Cities', Proceedings of the National Academy of Sciences of the United States of America 104, no. 18 (2007): 7588-93.

${ }^{26}$ Richard J. Hatchett, Carter E. Mecher, and Marc Lipsitch, 'Public Health Interventions and Epidemic Intensity during the 1918 Influenza Pandemic', Proceedings of the National Academy of Sciences of the United States of America 104, no. 18 (2007): 7582-7.

${ }^{27}$ Ibid.

${ }^{28}$ Howard Markel et al., 'Nonpharmaceutical Interventions Implemented by US Cities during the 1918-1919 Influenza Pandemic', Journal of the American Medical Association 298, no. 19 (2007): 644-55.
} 
public places in mid October, reopening the state three weeks later. ${ }^{29}$ This rather quick reopening of the state led to a subsequent peak in some cities, most notably Grand Rapids. ${ }^{30}$

In the Caribbean, the autumn wave began in September 1918 and lasted through December. ${ }^{31}$ It spread across South America between October and December, with reports from Brazil coming as early as September. In Chile, the autumn 1918 wave stretched from October 1918 to February 1919. ${ }^{32}$ On the African continent, Sierra Leone was struck early in September, and South Africa experienced an epidemic from September to December 1918. Countries in Asia experienced an autumn wave from September to December 1918, and Oceania's autumn wave lasted from October to December. ${ }^{33}$

From the above description, it can be seen that the autumn 1918 wave showed a great deal of global synchronicity, with nearly every part of the world, regardless of climate or region, experiencing a wave which started between August and October 1918 and then continued for two or more months depending on whether NPIs were implemented and other local factors. A notable exception to this pattern is Australia, where implementation of a strict quarantine delayed the arrival of a second wave until January 1919. ${ }^{34}$ Notably, Australia's second wave, which peaked in February 1919, emerged outside the southern hemisphere flu season. ${ }^{35}$ In addition, this and two subsequent waves (in April and July 1919) in Australia were shorter than in many other locations, perhaps because the hot climate and sparse population were less favourable for transmission.

\section{Wave 3: the 'trailer' wave}

Across regions and climate zones, there is evidence that the pandemic continued into early 1919, either as an extension of a late 1918 wave or as a recurrence in the form of a third wave. ${ }^{36}$ Initial analysis indicates that this phenomenon may have been influenced by climate; the waves were more defined and often extended longer in northern latitudes. For example, waves in the northern US and in Canada lasted until March 1919, while Sweden was still experiencing a wave in April $1919 .{ }^{37}$ In Chile, this trailer wave lasted from July 1919 to February $1920 .{ }^{38}$ Brazil appears to have experienced a wave from January to June 1919.

\section{Wave 4: the 1920 wave}

A fourth wave struck a number of countries, including Canada, Japan, Taiwan, and parts of the US, in February $1920 .{ }^{39}$ Evidence from locations such as Michigan in the USA suggest that this

\footnotetext{
${ }^{29 ،}$ Governor Sleeper Issues Proclamation Closing State Because of Influenza Spread', Grand Rapids Herald, 19 October 1918; 'State to Open Within a Week', Detroit News, 2 November 1918, both digitized at University of Michigan Influenza Encyclopedia, http://www.influenzaarchive.org.

${ }^{30}$ 'Grand Rapids, Michigan', University of Michigan Influenza Encyclopedia, http://www.influenzaarchive.org/cities/citygrandrapids.html\#.

${ }^{31}$ Patterson and Pyle, 'Geography and Mortality'; USPHC, Public Health Reports, 1918-1920.

${ }^{32}$ Gerardo Chowell, Lone Simonsen, J. Flores, M. A. Miller, and Cécile Viboud, 'Death Patterns during the 1918 Influenza Pandemic in Chile', Emerging Infectious Diseases 20, no. 11 (2014): 1803-11. https://doi.org/10.3201/eid2011.130632.

${ }^{33}$ Siddharth Chandra, 'Mortality from the Influenza Pandemic of 1918-19 in Indonesia', Population Studies 67, no. 2 (2013): 185-93.

${ }^{34}$ Patterson and Pyle, 'Geography and Mortality'.

${ }^{35}$ USPHC, Public Health Reports January-June, 1919.

${ }^{36}$ USPHC, Public Health Reports, 1918-1919.

${ }^{37}$ Chandra et al., 'Short-Term Birth Sequelae'; USPHC, Public Health Reports, 1918-1920.

${ }^{38}$ Chowell et al., 'Death Patterns'.

${ }^{39}$ Chandra et al., 'Pandemic Re-emergence'; Siddharth Chandra and Yan-Liang Yu, 'The 1918 Influenza Pandemic and Subsequent Birth Deficit in Japan', Demographic Research 33, no. 11 (2015): 313-26; Akira Hayami, The Influenza Pandemic in Japan, 1918-1920: The First World War between Humankind and a Virus, trans. Lynne E. Riggs and Manabu Takechi (Kyoto: International Research Center for Japanese Studies, 2015); Ying-Hen Hsieh, 'Excess Deaths and Immunoprotection during 1918-1920 Influenza Pandemic, Taiwan', Emerging Infectious Diseases 15, no. 10 (2009): 1617-19;. Dahal, M. Jenner, L. Dinh, K. Mizumoto, C. Viboud, and G. Chowell, 'Excess Mortality Patterns during
} 
wave of excess mortality was caused by the same virus that caused the waves of infection and mortality in autumn 1918 and early 1919. Specifically, the 1920 wave was marked by the signature feature of the autumn 1918 wave: a disproportionate level of mortality among people in the prime of their lives. ${ }^{40}$ Brazil experienced a recurrence in February 1920, and a wave occurred in parts of Chile between June and December 1921. The occurrence of this later wave during the flu seasons in the northern and southern hemispheres is suggestive of a pattern of the disease 'settling into' the standard seasonal pattern of influenza epidemics.

\section{Connectivity: a key human factor}

Accounts of the influenza-18 pandemic identify three types of global networks that enabled the spread of the influenza. These are military networks, active during the First World War, colonial networks, and trade networks. ${ }^{41}$ While single-country studies have focused primarily on modes of dispersion within countries, especially land transportation networks including railway lines and roads, this article, with its global focus, emphasizes both land- and sea-based modes of connectivity. ${ }^{42}$

The influenza-18 pandemic is remarkable for the speed with which it spread to all corners of the Earth, first carried by military transport networks and eventually spreading into civilian populations. The year 1918 marked the fourth year of the First World War and a time when the USA was rapidly deploying troops to Europe to fight on behalf of the Triple Entente and its allies. The initial wave of the pandemic spread radially outwards from the Midwestern US to various military training stations, and from there was carried to Europe by soldiers bound for the front. ${ }^{43}$ In Europe, the widespread trench warfare provided favourable conditions for the spread of the virus. From there, influenza spread rapidly to European colonies from the metropole along shipping lines: as the First World War wound down in late 1918 and troops started to return home to the various countries from which they had come, they took the disease with them, thereby contributing to its dispersal across the globe.

A second key form of connectivity in 1918 was the colonial system. The colonial powers of Europe maintained frequent contact with their colonies in the Americas, Africa, and Asia, providing a second avenue for transmission. Some of this connectivity naturally overlapped with military networks. For example, more than one million British Indian troops were transported to the various theatres in the First World War. Notably, the epidemic first appeared in the port of Bombay on the west coast of British India about a month before it appeared in England, introduced by ships and rapidly dispersing along the railway network to the rest of the colony. ${ }^{44}$ In July, at around the same time that the virus was first being reported in Britain, it also appeared in Australia and New Zealand, indicating possible introduction from either Britain or British India by military or civilian transport. Dutch-administered Sumatra experienced an outbreak

1918-1921 Influenza Pandemic in the State of Arizona, USA', Annals of Epidemiology 28, no. 5 (2018): 273-80; Chandra et al., 'Short-Term Birth Sequelae'.

${ }^{40}$ Michigan Department of Health, Forty-Seventh Annual Report of the Commissioner of the Michigan Department of Health for the Fiscal Year Ending June 30, 1919 (Lansing, MI: Michigan Department of Health, 1920), 146; Michigan Department of Health, Forty-Ninth and Fiftieth Annual Report of the Commissioner of the Michigan Department of Health for the Fiscal Years Ending June 30, 1921 and June 30, 1922 (Lansing, MI: Michigan Department of Health, 1922), 145.

${ }^{41}$ Humphries, 'Paths of Infection'.

${ }^{42}$ Olivia Reyes, Elizabeth C. Lee, Pratha Sah, Cécile Viboud, Siddharth Chandra, and Shweta Bansal, 'Spatiotemporal Patterns and Diffusion of the 1918 Influenza Pandemic in British India', American Journal of Epidemiology 187, no. 12 (2018): 2550-60; Howard Phillips, In a Time of Plague: Memories of the 'Spanish' Flu Epidemic of 1918 in South Africa (Cape Town: Van Riebeeck Society, 2018); Patterson, 'Influenza Epidemic'; P. B. van Steenis, 'Enkele Epidemiologische Opmerkingen Aangaande de Griep in de Afdeeling Magelang 1918' ('Some Epidemiological Comments Regarding the Flu in the Magelang Department'), Geneesdkundig Tijdschrift voor Nederlandsch Indie (Medical Journal for the Dutch East Indies) 59 (1919): 901-20.

${ }^{43}$ Patterson and Pyle, 'Geography and Mortality', 5.

${ }^{44}$ Reyes et al., 'Spatiotemporal Patterns and Diffusion'. 
in June 1918, introduced from British Malaya, across the Strait of Malacca. Thus, involvement in the First World War accelerated the transmission of the virus from the metropole to the colonies, and networks linking the various nodes of the British empire appear to have played a significant role in the spread of the spring 1918 wave.

The far more virulent autumn 1918 wave spread more rapidly than the spring 'herald wave'. Although some of the colonial patterns are murkier owing to the sheer speed with which the virus spread, they are still visible, primarily in the timing of the virus's introduction. The clearest indicator of the colonial phenomenon is the arrival of the wave in Freetown, Sierra Leone on the British transport ship SS Mantua, and in South Africa, where troop transports brought the virus to Cape Town in September $1918 .{ }^{45}$ The role of colonial networks in the introduction of the virus is visible in other locations in West Africa as well. French-held Senegal and the Ivory Coast were infected in August 1918, around the same time that the influenza appeared in western France. Significantly, West African tirailleurs had fought with the French army during the war. ${ }^{46}$ In addition to the French and British empires, Japan's burgeoning colonial empire in the Pacific may have facilitated the spread of the virus to its colonies in Taiwan and Korea. Patterson and Pyle rule out the Trans-Siberian railway as a route of introduction to southern Korea (specifically Seoul), leaving open the question of where the infection came from in September $1918 .{ }^{47}$ On their map of the worldwide diffusion of influenza, a 'circle of infection' is visible in the East China Sea, with southern Japan, Korea, Taiwan, and Fujian, China all becoming infected in September $1918 .{ }^{48}$ This timing suggests that colonial transport between Kyushu, Taiwan, and the southern Korean peninsula may have introduced the virus to those locations.

The global trading network complemented the military and colonial networks, providing a third avenue for transmission. While much of the trading network overlapped with individual colonial networks, shipping from the colonies did not always follow colonial routes. For example, ships from the Dutch East Indies (now Indonesia) travelled not only to the Netherlands but also to British colonies. The Netherlands were neutral during the First World War, which meant that few troop transports were moving between the metropole and the colonies. This fact would make an introduction from neighbouring British Malaya across the Strait of Malacca more likely than an introduction from the Netherlands, located thousands of miles away. Similarly, while neutral Portugal was infected in August 1918, the rapidity with which the virus spread from France and Britain to their colonies in Africa was not replicated in the Portuguese colonies of Mozambique and Angola. The virus was introduced to Portugal's colonies much later, around November 1918. The fact of being a colony, therefore, was not a guarantee of synchronic patterns of infection with the metropole, and other networks contributed to the global spread of the pandemic.

\section{Seasonality: a key natural factor}

The role of seasonality and climate must be considered when developing a picture of the influenza18 pandemic as a global event, even if human factors like connectivity may have played more important roles in shaping the overall patterns in its early stages. ${ }^{49}$ An advantage of taking a global perspective of the influenza-18 pandemic is that the variation in seasons across countries in the

\footnotetext{
${ }^{45}$ Patterson and Pyle, 'Geography and Mortality, 8-9; Howard Phillips, 'South Africa's Worst Demographic Disaster: The Spanish Influenza Epidemic of 1918', South African Historical Journal 20, no. 1 (1988): 57-73.

${ }^{46}$ Joe Lunn, "Les races guerrières": Racial Preconceptions in the French Military about West African Soldiers during the First World War', Journal of Contemporary History 34, no. 4 (1999): 517-36.

${ }^{47}$ Patterson and Pyle, 'Geography and Mortality', 10-11.

${ }^{48}$ Ibid., 10.

${ }^{49}$ For a review of this subject, see James Tamerius, Martha I. Nelson, Steven Z. Zhou, Cécile Viboud, Mark A. Miller, and Wladimir J. Alonso, 'Global Influenza Seasonality: Reconciling Patterns Across Temperate and Tropical Regions', Environmental Health Perspectives, 119, no. 4 (2011):439-45.
} 
far-flung reaches of the globe can shed light on a phenomenon that is not yet well understood: the process by which a disease caused by a novel virus transitions from a pandemic to a less threatening (but still harmful) seasonal phenomenon.

Influenza is understood to be a seasonal illness, and research indicates that viral transmission is influenced by temperature and relative humidity. For example, Lowen et al. identified 5 degrees Celsius and low relative humidity as ideal conditions for transmission. ${ }^{50}$ Their data implicate low relative humidities produced by indoor heating and cold temperatures as features of winter that favor influenza virus spread'. ${ }^{51}$ This aligns with generally accepted patterns of flu seasonality in the northern hemisphere. According to the US Centers for Disease Control and Prevention, 'In the Northern Hemisphere, the flu season can begin as early as October and can last as late as April or May. In the temperate regions of the Southern Hemisphere, influenza activity typically occurs during April - September. In the tropics, influenza activity occurs throughout the year. ${ }^{52}$

As outlined in the preceding account of the waves of the pandemic, the first wave in North America and Europe was more prolonged than elsewhere in the world, possibly because the northern latitudes had more favourable conditions for transmission. By contrast, Australia's three waves were shorter and more well defined, perhaps owing to less favourable transmission conditions in the subtropical/tropical country. The widespread influenza activity into the early months of 1919 also needs to be examined to determine if it was an extension of the autumn 1918 wave or constituted a third, separate wave. Countries and regions spanning northern latitudes, including Sweden, Russia, the northern US, and Canada, reported cases later into 1919. ${ }^{53}$ This again suggests a role for the more favourable climatic conditions in these northern latitudes, with the timing of these waves generally aligning with the northern hemisphere's flu season.

Locations around the world - the USA, Canada, New Zealand, Finland, Brazil, and others experienced spikes in influenza cases and deaths in early 1920. As the example of Brazil shows, this was not confined to colder latitudes as might have been expected. In Michigan, the age profile of mortality from this wave suggests that it was the same virus as the deadly 1918 wave. ${ }^{5}$ This phenomenon warrants further investigation to determine whether it was as widespread a phenomenon as the other waves, but was previously overlooked as part of the pandemic owing to the temporal separation. ${ }^{55}$

It is quite clear that, in the early stages of the influenza-18 pandemic, factors such as transportation networks and transmissibility largely overcame seasonality and climatic factors as determinants of timing. The near-simultaneous emergence of the autumn 1918 wave across the globe, regardless of season, is unambiguous evidence of this. It is unclear at this stage whether temperature and humidity had an impact on other factors such as transmissibility or mortality rates in different locales. Nonetheless, seasonality and climate should not be completely discounted as factors influencing the timing of the early waves: it is possible that they predisposed some areas to extended or recurrent waves of infection and mortality.

\footnotetext{
${ }^{50}$ Lowen et al., 'Influenza Virus Transmission'.

${ }^{51}$ Ibid.

${ }^{52} \mathrm{CDC}$, 'Influenza Prevention: Information for Travelers', 31 July 2018, https://www.cdc.gov/flu/school-business/ travelersfacts.htm.

${ }^{53}$ USPHC, Public Health Reports, 1918-1920; Chandra et al., 'Short-Term Birth Sequelae'.

${ }^{54}$ Michigan Department of Health, Forty-Ninth and Fiftieth Annual Report, 145.

${ }^{55}$ Notably, the website of the CDC excludes the 1920 wave from its graphical representation of the influenza-18 pandemic. See CDC, '1918 Pandemic Influenza: Three Waves', 11 May 2018, https://www.cdc.gov/flu/pandemic-resources/1918commemoration/three-waves.htm.
} 


\section{How pandemic waves would have reflected the combined factors of connectivity and seasonality}

In order to understand how connectivity and seasonality may have interacted to produce the patterns observed in 1918-20, we now interpret the observations presented in the above sections on connectivity and seasonality using the framework of a compartmental model in infectious disease epidemiology. Briefly, compartmental models allocate people to each of a number of compartments, depending on their status. The simplest model is the three-compartment SIR model, consisting of susceptible (S), infectious (I), and recovered (or removed, R) people. In the case of a novel virus, the entire population is initially susceptible. As the epidemic progresses, people in the population transition from being susceptible to infectious to recovered (or deceased). It is possible for people to remain susceptible but uninfected for the duration of the epidemic. Depending on the nature of the disease, people who become infectious are assumed to become immune to the disease for a specified duration. The degree to which a virus can penetrate a population will depend at least in part on the number of susceptible people in that population, in addition to a variety of other factors, including but not restricted to crowding, the reproduction number of the virus (explained above), and conditions of temperature and humidity. ${ }^{56}$

As the virus spreads and infects increasing numbers of people, those who are exposed and then recover are often immune to a subsequent round of infection, at least for a period of time. Once the epidemic has sufficiently penetrated the population, a large fraction of the population will have acquired immunity, and the likelihood of an infected person encountering a susceptible person will diminish to the point that the reproduction number will fall below 1.0, thereby extinguishing the epidemic.

Therefore, a novel virus encountering an entirely susceptible population would have far more opportunities to survive and propagate than would a virus to which a significant fraction of the population has already been exposed and is therefore immune. At the outset of the influenza-18 and COVID-19 pandemics, large fractions of the population in any location would have been susceptible. In the early stages, therefore, other factors that can come into play to create or extinguish an epidemic wave, such as weather, would have been less important in determining the course of the pandemic than the sheer size of the susceptible populations. However, as the first epidemic wave played out and subsequent waves emerged and re-emerged, the dominant influence of an initially large pool of susceptible people would have diminished relative to other factors such as weather, and the disease would have 'settled in' and taken on the characteristics of a seasonal disease, which affects only that limited segment of the population that is susceptible owing to lack of prior infection and immunization or for which the immunity acquired from a previous infection may have worn off.

\section{Discussion and conclusions}

Keeping the above epidemiologic background in mind, we can now consider the material we have presented on waves of the influenza pandemic of 1918-20, with a focus on the timing and number of waves, the locations in which they emerged, and the degree to which they were synchronized with waves in other locations. A look at this pattern over time gives us clues about the process by which a novel virus encounters an immunologically naïve population, and how it settles in for the long haul when it is no longer novel in the immunological sense.

\footnotetext{
${ }^{56}$ W. Kermack and A. McKendrick, 'Contributions to the Mathematical Theory of Epidemics - I', Bulletin of Mathematical Biology 53, no. 1-2 (1991): 33-55; W. Kermack and A. McKendrick, 'Contributions to the Mathematical Theory of Epidemics - II: The Problem of Endemicity', Bulletin of Mathematical Biology, 53, no. 1-2 (1991): 57-87; W. Kermack and A. McKendrick, 'Contributions to the Mathematical Theory of Epidemics - III: Further Studies of the Problem of Endemicity', Bulletin of Mathematical Biology, 53, no. 1-2 (1991): 89-118.
} 
In the early stages of the pandemic, when and where waves of infection emerged was driven primarily by human interactions and connectivity. The large pool of susceptible people worldwide meant that the tinder for a conflagration was readily available and all that was needed was the spark in the form of infectious individuals. The timing of the emergence of the virus could not have been more unfortunate. The First World War, located primarily in what was then the metropole of the colonial system, Europe, was coming to an end, and large numbers of troops were returning to the colonies across the globe. The virus went with them, finding large and often under-nourished populations of people to infect. The synchronicity with which the autumn 1918 wave emerged is both stunning and revealing of the degree to which the colonial system had facilitated globalization.

The influenza-18 pandemic spread rapidly around the world, reaching nearly every inhabited area within just a few months, and most locations experienced waves within a four-month timeframe in the autumn of 1918. In other words, a globally synchronized, rapidly spreading pandemic is not unique to the hyper-globalized world of the twenty-first century. Though factors such as air travel undoubtedly accelerated the spread of COVID-19 in early 2020, modern modes of travel and trade are not necessary conditions for the rapid spread of a global pandemic; sufficient connectivity and transmissibility, enhanced by the novelty of the pathogen and the ease of spread owing to its respiratory nature, combined to produce the synchronous global influenza-18 pandemic a century ago.

As the influenza-18 pandemic spread across the globe and infected increasing numbers of people, it also reduced the number of susceptible people available for infection. In the later stages of the pandemic, therefore, the mere reintroduction of the virus into a location was no longer sufficient to cause a wave of infections. Other factors, including but not restricted to weather, probably came into play. The result was that, in the later stages of the pandemic, a greater tendency toward seasonality emerged - a 'settling-in' phenomenon that we see in 1920 data. $^{57}$

Descendants of the novel H1N1 virus that caused the influenza-18 pandemic are in circulation today. As recent research has shown, they follow a seasonal pattern in their emergence and reemergence from year to year. ${ }^{58}$ If the interaction between connectivity and seasonality proposed above holds, then one would expect to see the irregular wave pattern from a pandemic gradually converge to a seasonal pattern of emergence, in the winter months of May to August in the southern hemisphere and November to February in the northern hemisphere. This would be indicative of convergence to an equilibrium marked by strong patterns of seasonality.

Although the influenza virus dispersed rapidly around an interconnected world in 1918, there was no global coordination to match this spread. Diplomacy was far less advanced than it is today; the founding of the League of Nations was still two years away, and there was no international public health agency that could have alerted governments to the emergence of a new pathogen, recommended best practices for containment, and assisted in treatment research, as the World Health Organization does today. Had such an organization existed, wartime conditions would likely have made it impossible for its advice to be followed anyway, especially in Europe, where trench warfare played a central role in the early spread of the pandemic.

The closest substitute for international organizations at the time would have been the globespanning colonial empires that partially facilitated the virus's spread. However, even within these empires, epidemic control practices were not standardized. Australia, which by this point was largely autonomous from Britain, imposed a strict quarantine that kept the autumn wave of the virus at bay until 1919, a practice that was not replicated by even its close neighbour,

\footnotetext{
${ }^{57}$ Taubenberger and Morens, '1918 Influenza'.

${ }^{58}$ Brian S. Finkelman, Cécile Viboud, Katia Koelle, Matthew J. Ferrari, Nita Bharti, and Bryan T. Grenfell, 'Global Patterns in Seasonal Activity of Influenza A/H3N2, A/H1N1, and B from 1997 to 2005: Viral Coexistence and Latitudinal Gradients', PLoS ONE, 2, no. 12 (2007), https://doi.org/10.1371/journal.pone.0001296.
} 
New Zealand, also a nominal British colony. ${ }^{59}$ New Zealand suffered a severe wave of infection and mortality in the autumn of 1918 and continued to receive ships from the US, likely passing the infection on to Australia in 1919 after its quarantine was lifted. ${ }^{60}$ Australia was the successful exception rather than the rule in epidemic control, however, and international travel and trade continued largely unabated throughout the pandemic.

A similar diversity of approaches was taken with respect to social distancing measures, recognized today as one of the most effective ways to control the spread of the ongoing viral pandemic. In Australia, for example, public gathering places were closed, people were required to wear masks, quarantine facilities were created, and the movements of people were restricted. ${ }^{61}$ In addition, regular handwashing, good ventilation, and other forms of good hygiene were promoted. ${ }^{62}$ Recent research has shown that such social distancing measures significantly reduced the transmission of the 1918 influenza virus. ${ }^{63}$ In Chile, handwashing was encouraged and streets were regularly disinfected. ${ }^{64}$ In Liverpool, quarantine and social distancing measures were implemented, and the benefits of personal hygiene including handwashing and not sharing utensils for eating were promoted. ${ }^{65}$ While difficult to prove, these measures may have had a beneficial impact: British India, where the high population density discouraged authorities from undertaking what they deemed would be a futile task, suffered one of the highest death tolls, in both absolute and percentage terms, in the world. In the context of the COVID-19 pandemic, the beneficial effects of social distancing measures are clearly visible: in the USA for example, a number of states were able to control infections by maintaining social distancing measures, only to see them increase when these measures were relaxed.

This article has demonstrated the role that a global and historical perspective can play when examining a global pandemic like the 1918-20 influenza pandemic. Insights gained from viewing the world as a whole can complement those obtained from the dozens of studies of single or a few countries. As the world struggles with the COVID-19 pandemic, how human and viral populations adapt to one another will remain an important topic of research. A central question in this research will be the issue of whether the two populations will converge to an equilibrium and, if so, what the nature of that equilibrium will be. If the SARS-CoV-2 virus is anything like the H1N1 virus, then we should expect multiple waves of infection and fatalities until a vaccine or cure is developed or sufficient numbers of people become infected and acquire immunity to the virus. These waves could continue to emerge years after the detection of the first case in Wuhan in December 2019. Further, it is likely that, if this virus is anything like other members of the coronavirus family, it will settle into a seasonal pattern of infection after the global population gains immunity to COVID-19 through infection or inoculation.

Siddharth Chandra is Director of the Asian Studies Center and Professor of Economics in James Madison College at Michigan State University with a courtesy appointment in the Department of Epidemiology and Biostatistics. His research interests include the 1918 influenza pandemic with a focus on Asia and the USA, genocide and politicide in Asia with a focus on Bangladesh and Indonesia, and behaviour and policy relating to addictive substances with a focus on India and

\footnotetext{
${ }^{59}$ Patterson and Pyle, 'Geography and Mortality', 9.

${ }^{60} \mathrm{P}$. Curson and K. McCracken, 'An Australian Perspective of the 1918-1919 Influenza Pandemic', New South Wales Public Health Bulletin 17, no. 7-8 (2006): 103-7.

${ }^{61}$ Ibid., 103.

${ }^{62}$ Ibid.

${ }^{63}$ Peter Caley, David J. Philp, and Kevin McCracken, 'Quantifying Social Distancing Arising from Pandemic Influenza,' Journal of the Royal Society Interface 5 (2008): 631-9.

${ }^{64}$ Hugo Alberto Maureira, "Los culpables de la miseria": poverty and public health during the Spanish influenza epidemic in Chile, 1918-1920' (PhD diss., Georgetown University, Washington, DC, 2012), 180.

${ }^{65}$ Charlotte Hadfield, 'Social Distancing in Liverpool during Spanish flu Pandemic of 1918 and How Restrictions were Lifted', Echo, 3 May 2020, https://www.liverpoolecho.co.uk/news/liverpool-news/social-distancing-liverpool-duringspanish-18139281.
} 
Indonesia. His work spans the fields of demography, economics, epidemiology, geography, history, political science, public policy, and psychology.

Julia Christensen has a BA in International Relations from James Madison College at Michigan State University with minors in political economy and Russian language. She presently works as a human geographer. Her research interests centre on emergent national security challenges, including the impact of pandemics on stability and economics, and the intersection of migration, climate change, and conflict.

Shimon Likhtman is a student in James Madison College at Michigan State University majoring in Social Relations and Policy with a minor in Science, Technology, Environment, and Public Policy Studies. His interests include social history, environmental policy, and public health. After the completion of his studies he intends to pursue a career in public health research.

Cite this article: Chandra S., Christensen J., and Likhtman S. 2020. Connectivity and seasonality: the 1918 influenza and COVID-19 pandemics in global perspective. Journal of Global History 15: 408-420, doi:10.1017/S1740022820000261 